\title{
DETERMINATION OF DEFORMATIONS AND OF INDIRECT STRESS IN THE DOUBLE HULL PANEL BY FEM IN A CONTAINER SHIP OF 3451 TEU
}

\author{
Anişoara - Gabriela Cristea \\ "Dunarea de Jos" University of Galati, \\ Faculty of Naval Architecture, Galati, Domneasca Street, No. 47, 800008, Romania, \\ E-mail: anisoara.cristea@ugal.ro
}

\begin{abstract}
This paper presents the determination of deformations and of indirect stress in the double hull panel by FEM in a container ship of 3451 TEU. The idea of FEM consists in modeling the field studied through a set of finite-size elements, connected to each other in a number of nodal points in which solution is searched. The relationship between generalized displacements and generalized forces of an element is made through the stiffness matrix, usually obtained on the Ritz or Galerkin methods. To be more certain about the results obtained from the analysis, a more complex structure has been built that gives a more accurate construction of the ship.Following the comparisons made between the analyzes of the two structures, the results are recorded in a chart where one can easily see the differences and similarities between the two results.
\end{abstract}

Keywords: normal stresses, specific deformations, numerical modeling.

\section{INTRODUCTION}

The basics of the finite element analysis were first formulated in 1943 by the German mathematician Richard Courant who, combining the Ritz method ([1], [2], [3]) with numerical analysis in variance and minimization calculations, obtained satisfactory solutions for the analysis of vibration systems. Finite Element Method has experienced rapid development in tandem with the growth of computing capabilities and has imposed itself as a general numerical method for solving the most complex problems in the field of continuous elastic structures, from civil engineering to aviation and maritime ships.

The idea of finite element method (FEM) consists of modeling the field studied by a series of finite dimension elements, connected to each other by nodes. The operation is called meshing in finite elements. In the bending plates, the nodes of the finite elements determine $\mathrm{w}$ movements and their derivatives, which are called generalized displacements or degrees of freedom. The connection between the elements is accomplished in the assembly process, which consists in writing the equations of equilibrium of the nodes to which external forces or forces of interaction between the elements are applied. The relationship between the generalized displacements and the generalized forces of an element is realized by means of the stiffness matrix, which is obtained by the Ritz or Galerkin method.

\section{FINITE ELEMENT MODELING}

To be able to perform the structural analysis, it is necessary for the structure to be modeled, to be assigned boundary conditions, 
conditions that are chosen depending on what you want to analyze and on the extension of the model, to model and establish loads, and finally the analysis is performed and the results obtained in model analysis are interpreted.

The models analyzed can be:

- global models;

- local models;

- models that extend over a certain length of the ship;

Following structural analyzes the following are obtained:

- their own modes of vibration;

- reaction of structural elements to loss of stability;

- states of deformations and strains for a particular load case.

In the case of models extending over a certain length of the ship, as well as for the local models certain boundary conditions are required, as stresses from the general bending of the ship must be correct so as not to influence the results obtained in the analysis area.

\subsection{Purpose}

The purpose of this calculation is to verify strains and deformations for a planking of a container ship with a capacity of 3451 TEU. The calculation was made by the Finite Element Method using NX. Nastrax/Femap 11.1.2 software ([4], [5]).

\subsection{Midship section}

With the base represented by the midship section of a container ship with a capacity of 3451 TEU the modeling of the double hull panel was made by the Finite Element Method with the aid of Femap 11.1.2 ([4], [5]) software using quadrilateral plate elements (shell 4T).

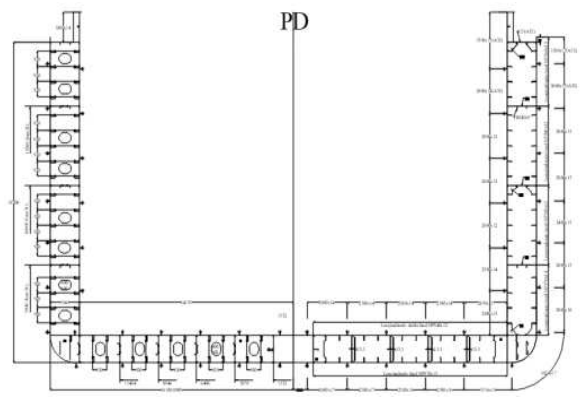

Fig. 1 Midship section

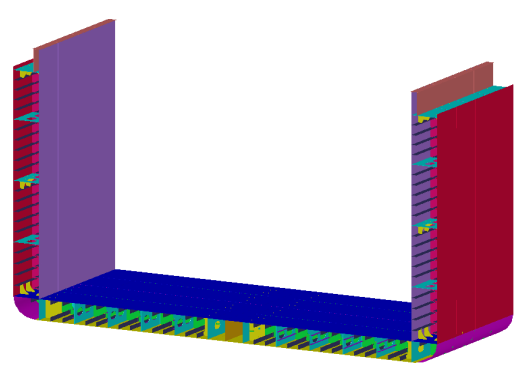

Fig. 2. CAD model

2.3 Units of measurement used for the model

- Length - millimeters (mm);

- Pressure - Megapascal (N/mm²);

- Mass - Kilogram (kg).

2.4 Axle system used

- X Axis - Transversal, positive to the portside;

- Y Axis - vertical, positive upwards;

- X Axis - Longitudinal, positive from stern to bow.

\subsection{Materials}

The material used is steel with the following properties:

- Young's modulus - $\mathrm{E}=2.1 \times 10^{5} \mathrm{~N} / \mathrm{mm}^{2}$;

- Poisson's ratio $-v=0.3$;

- Density of steel $-\rho=7.85 \times 10^{-6} \mathrm{~kg} / \mathrm{mm}^{3}$. 


\section{MODEL SUBJECT TO ANALYSIS}

The model was made by building its geometry, consisting of points, curves, surfaces, then, using manual meshing of surfaces, the model made up of nodes and elements was achieved. In the case of quadrilateral elements, interior angles must be larger than $60^{\circ}$, but not more than $120^{\circ}$.

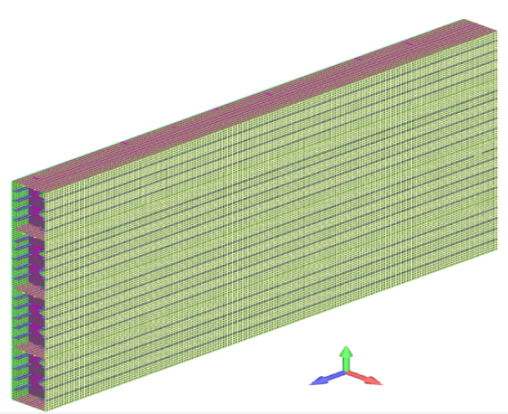

Fig. 3 Model subject to analysis

\section{BOUNDARY CONDITION}

Due to the fact that the model is just a part of the ship, it is necessary to block certain rotations and displacements at its ends to simulate the rest of the ship.

For the model analyzed the boundary conditions are:

- Conditions for locking the longitudinal, transverse, horizontal displacements and rotations of the stringer underlying the model, located in the continuity of the double bottom (All DOF - All degrees of freedom, $T_{x}$, $\mathrm{T}_{\mathrm{y}}, \mathrm{T}_{\mathrm{z}}, \mathrm{U}_{\mathrm{x}}, \mathrm{U}_{\mathrm{y}}, \mathrm{U}_{\mathrm{z}}=0$ );

- Conditions for locking transverse displacements at the intersection of the shell of the double board and the floor ( $\mathrm{Db} \cap \mathrm{C}_{1 \mathrm{pv}}, \mathrm{C}_{1 \mathrm{pp}}-$ $\mathrm{U}_{\mathrm{Y}}=0$ ).

Due to the fact that containers do not act on the double-hull board, the loads acting on the model are the hydrostatic pressures applied to the outer shell. Pressure due to the fluid environment is $1.025 \mathrm{t} / \mathrm{m}^{3}$. The ship is considered in still water at deep load draft $(\mathrm{h}=$ $12 \mathrm{~m})$.

Static sea pressure, Phys, is: where:

$$
\mathrm{P}_{\text {hys }}=\rho_{\mathrm{sw}} \mathrm{gT}_{\mathrm{LC}}
$$

$\rho_{\mathrm{sw}}-1.025 \mathrm{t} / \mathrm{m}^{3}$ - sea water density;

$\mathrm{T}_{\mathrm{LC}}-$ draft in $\mathrm{m}$;

$\mathrm{g}$ - Gravitational acceleration $9.81 \mathrm{~m} / \mathrm{s}^{2}$.

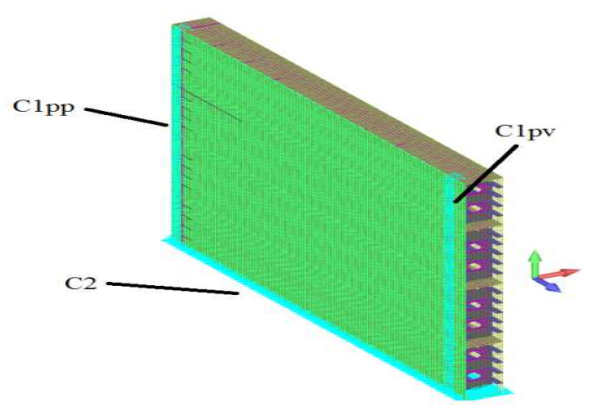

Fig. 4 Boundary conditions

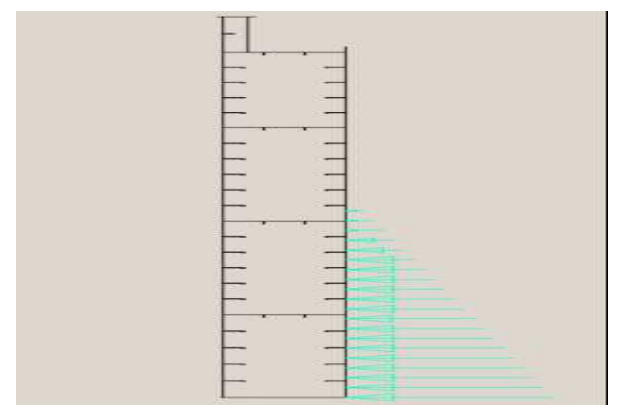

Fig. 5 Distribution of hydrostatic pressure

\section{THE RESULTS OF STATIC ANALYSIS}

After all the conditions and loads that have been applied to the structural model within this paper, the analysis and interpretation of the results obtained will be carried.

The results of structural model analysis are presented in the following figures. Stresses are grouped into separate groups for each element of the structure. 

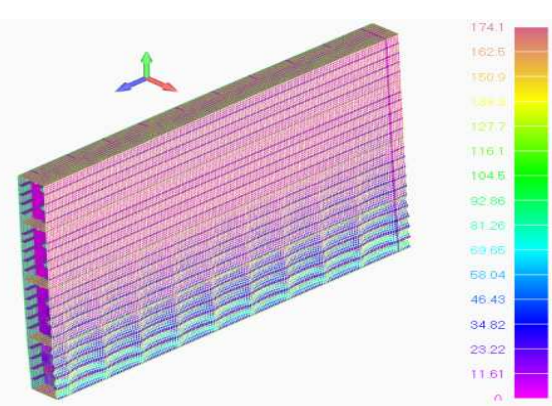

Fig. 6 Distribution of stress for the complete structure of the hull

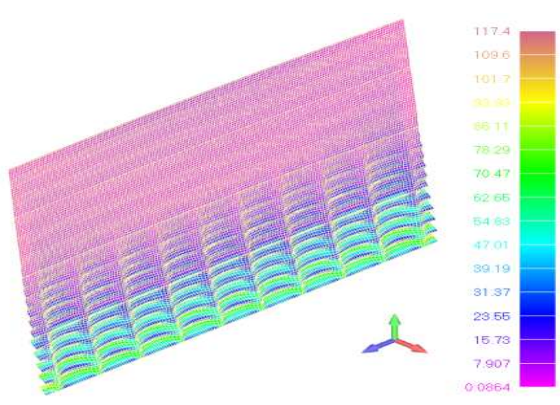

Fig. 7 Distribution of stress in the hull board

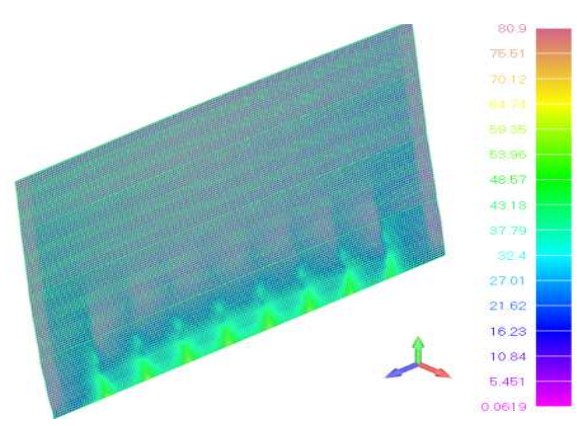

Fig. 8 Distribution of stresses on the double-hull board central area of a container ship with a capacity of $3451 \mathrm{TEU}$

The structural analysis was performed by the Finite Element Method with FEMAP 10.2. software.

Table 1 Results of the analysis

\begin{tabular}{|c|c|c|c|c|c|c|}
\hline Name & $\begin{array}{c}\text { Hull } \\
\text { board }\end{array}$ & $\begin{array}{c}\text { Dou- } \\
\text { ble- } \\
\text { hull } \\
\text { board }\end{array}$ & $\begin{array}{c}\text { Sup- } \\
\text { ports }\end{array}$ & $\begin{array}{c}\text { Floor } \\
\mathrm{s}\end{array}$ & $\begin{array}{c}\text { Plat } \\
\text { ban } \\
\mathrm{d}\end{array}$ & $\begin{array}{c}\text { Lon- } \\
\text { gitu- } \\
\text { dinals }\end{array}$ \\
\hline $\begin{array}{c}\sigma_{\max } \\
(\mathrm{MPa})\end{array}$ & 117.4 & 80.9 & 32.15 & 174.1 & 50.6 & 149.5 \\
\hline
\end{tabular}

After the analysis, we can observe that the Von Misses stress distribution records maximum values at the floors 174.1 $\mathrm{MPa}$, stress that does not exceed the maximum admissible value of $235 \mathrm{~N} / \mathrm{mm}^{2}$.

\section{COMPARATIVE STUDY}

To be more certain about the results obtained from the analysis, a more complex structure has been built that gives a more accurate construction of the ship. For the next model the same sheet-metal thicknesses and the same hydrostatic pressure applied on the outer sheath are used. Also, meshing of the elements of the double board will be done like in the previous model.

\subsection{Model analyzed}

For the model that is used in the comparative study we have achieved a more complex structure that gives a more accurate image of the hull of the ship. It contains, in addition to the previous model, the floors of the double bottom, central support and side supports, longitudinals of the bottom and double bottom, lateral support bands, brackets and bilge plates.

\section{CONCLUSIONS}

The structural model analysed was composed of a number of 78230 nodes.

The purpose of this chapter was to analyze resistance of the double board in the 


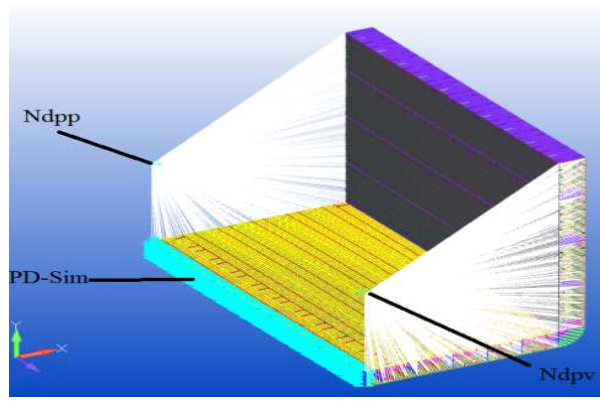

Fig. 9 The 3D FEM model together with the boundary conditions

\subsection{Boundary conditions for the model}

Table 2 Boundary conditions for the 3D - FEM model

\begin{tabular}{|c|c|c|c|c|c|c|}
\hline \multirow{2}{*}{$\begin{array}{c}\text { Boundary } \\
\text { condition }\end{array}$} & \multicolumn{5}{|c|}{ Blocked degrees of freedom } \\
\cline { 2 - 7 } & $\mathrm{Ux}$ & $\mathrm{Uy}$ & $\mathrm{Uz}$ & $\mathrm{Rx}$ & $\mathrm{Ry}$ & $\mathrm{Rz}$ \\
\hline $\begin{array}{c}\text { Stern master } \\
\text { node Ndpp }\end{array}$ & $\mathrm{x}$ & - & $\mathrm{x}$ & $\mathrm{x}$ & $\mathrm{x}$ & $\mathrm{x}$ \\
\hline $\begin{array}{c}\text { Bow master } \\
\text { node Ndpv }\end{array}$ & $\mathrm{x}$ & - & $\mathrm{x}$ & $\mathrm{x}$ & $\mathrm{x}$ & - \\
\hline $\begin{array}{c}\text { Symmetry in } \\
\text { the diametral } \\
\text { plane PD }\end{array}$ & - & - & $\mathrm{x}$ & - & $\mathrm{x}$ & - \\
\hline
\end{tabular}

\subsubsection{Boundary condition at the aft extremity}

After defining the master node (control point), using rigid elements (RB2) the slave nodes can be coordinated by the degrees of freedom of the Ndpv master node. Thus, at the stern of the model, the following degrees of freedom are blocked: Ux, Uz, Rx, Ry, Rz.

\subsubsection{Boundary condition at the bulbous bow}

After defining the master node (control point), using rigid elements (RB2) the slave nodes can be coordinated by the degrees of freedom of the Ndpv bow master node. Thus, at the bow of the model the following degrees of freedom: $\mathrm{Ux}, \mathrm{Uz}, \mathrm{Rx}, \mathrm{Ry}$ are blocked.
7.2.3 The symmetry condition in the diametral plane

The symmetry conditions in the diametral plane apply to all nodes disposed in the fore-and-aft line (PD). Thus, rotation in Zdirection and translations in $\mathrm{Y}$ direction are blocked.

\subsubsection{Pressure due to fluid on the outer shell}

Just like in the previous model, the pressure will be applied in the same way, with the ship considered in still water at deep load draft. The forces and pressures that act on the bottom and double bottom can be ignored for this comparative study due to the fact that they are not transmitted or are insignificantly transmitted to the shell.

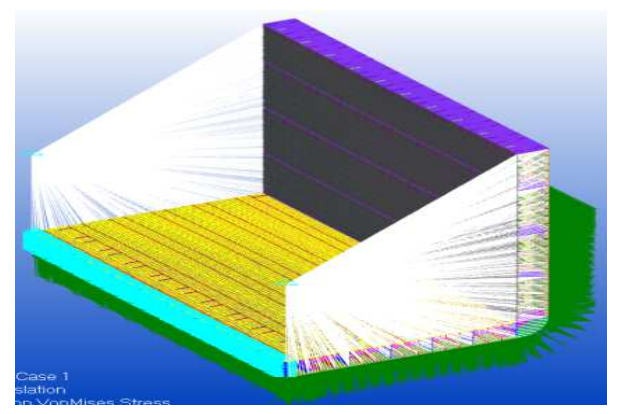

Fig. 10 Pressure distribution on the model

\section{CONCLUSIONS}

Following the comparisons made between the analyses of the two structures, the results are recorded in a chart where one can easily see the differences and similarities between the two results. As can be seen in the case of the plate, longitudinals, platbands and floors, there are no major differences in stress and the mode of stress occurrence is similar for both structures. 

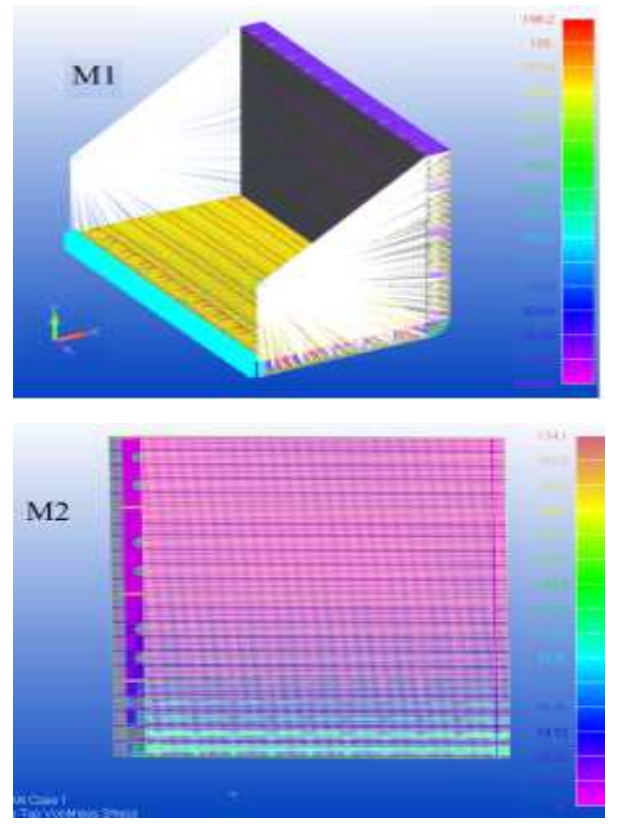

Fig. 11 Comparison of results of models
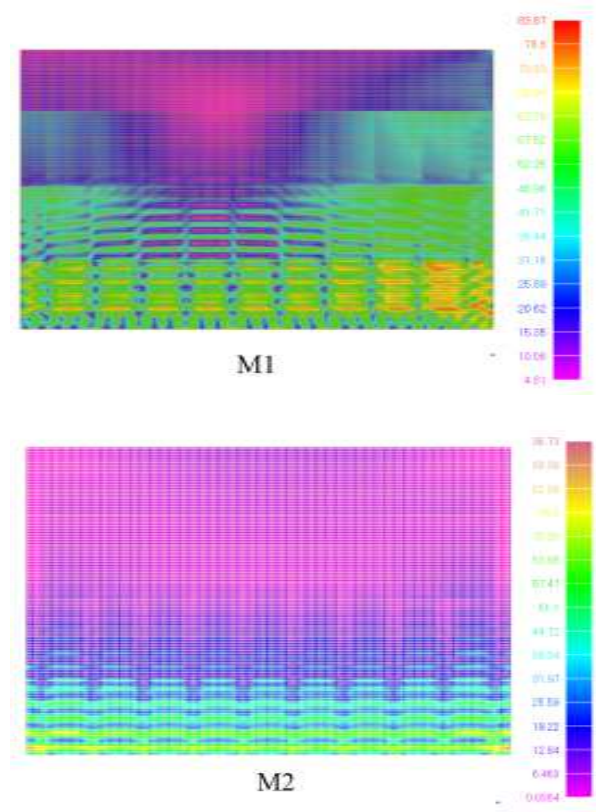

Fig. 12 Comparison of results of the plate analysis

The maximum stress to which the metal is subjected in both cases does not exceed the maximum of $235 \mathrm{~N} / \mathrm{mm}^{2}$.

The major differences that arise from the analysis of the two structures are in the area of stringers and double-hull board; this difference may occur due to the various boundary conditions applied on the two structures analyzed (standard model - M2 with all degrees of freedom blocked, and the more complex model - M1, where the boundary conditions are applied to the "master" nodes that are linked to the "slave" nodes by RIGID type elements).

\section{REFERENCES}

[1]. Cristea A.G., "Contribuții privind optimizarea structurilor de navă", Teză de doctorat, Galați, 2014

[2]. Domnişoru L., "Metoda elementului finit în construcţii navale. Aplicaţii", Editura Evrika, Brăila, 2003

[3]. Domnișoru L., Găvan E., Popovici O., "Analiza structurilor navale prin metoda elementului finit", Editura Didactică şi Pedagogică, Bucureşti, 2005

[4]. Domnişoru L., "Analiza structurilor navale prin metoda elementului finit . Aplicatii numerice", Editura Fundaţiei Universitare "Dunărea de Jos", Galaţi, 2009

[5]. $\mathbf{X} \mathbf{X} \mathbf{X}$ - Germanischer Lloyd, Rules and Guidelines, Part I Sea Going Ships. ed. 2016

[6]. $\mathbf{x} \mathbf{x} \mathbf{x}$ - FEMAP 9.3.1 / NX NASTRAN 5.0 User's Guide, UGS Corporation / Siemens PLM Software Inc., 2007

Paper received on December $31^{\text {th }}, 2018$ 